\title{
A fast-moving feature of westward drift
}

\author{
David R. Barraclough $\left({ }^{1}\right)$ and Stuart R.C. Malin $\left(^{2}\right)$ \\ ${ }^{1}{ }^{1}$ British Geological Survey, Murchison House, Edinburgh EH9 3LA, U.K. \\ $\left.{ }^{2}\right)$ Boğaziçi University, Kandilli Observatory and ERI, İstanbul, Turkey
}

\begin{abstract}
The dominant feature in the magnetic declination record at all European sites for which adequate data are available is a minimum between 1750 and 1860 . The time of minimum at different sites correlates well with longitude and implies a westward drift rate of $0.61 \pm 0.08^{\circ} \mathrm{yr}^{-1}$. This is greatly in excess of the widely adopted value of
$0.18^{\circ} \mathrm{yr}^{-1}$ for global westward drift.
\end{abstract}

Key words geomagnetic field - westward drift

\section{Introduction}

One of the longest and most complete series of magnetic declination, $D$, and dip, $I$, data is that for London from about 1570 to the present. The data have been compiled by Malin and Bullard (1981). They remark that «the overall pattern, with dip showing a maximum at about the time when declination is decreasing most rapidly, is highly suggestive of an electrical eddy current drifting westwards near the core surface». Following its rapid decrease, $D$ reached a minimum value in about 1820 and since then has been increasing more or less steadily. The Paris (Alexandrescu et al., 1996) and Rome (Cafarella et al., 1993) data show a similar pattern. While a few other sites have long series of $D$ data, historical $I$ data are very sparse and are not included in this study.

Mailing address: Dr. David R. Barraclough, British Geological Survey, Murchison House, West Mains Road, Edinburgh EH93LA, U.K.; e-mail: d.barraclough@bgs.ac.uk

\section{The fast-moving feature}

While compiling data for the Istanbul area, it was noticed that the $D$ record was similar to that for London, but with the minimum occurring some 50 years earlier. Could this be due to the same eddy current? If so, it would imply that it had been moving westward at about $0.6^{\circ} \mathrm{yr}^{-1}$, whereas the rate of drift deduced by Malin and Bullard (1981) from London data alone was $0.17^{\circ} \mathrm{yr}^{-1}$, in good agreement with the global estimates for westward drift (see, for example, Malin, 1969; Langel, 1987).

To check that it was, indeed, the same feature, a search was made of the BGS archives for long series of $D$ data for other sites. All of those in Europe and the North Atlantic with sufficient data to do so showed a similar pattern with a clearly defined minimum somewhere between 1770 and 1860. Moreover, the time of minimum showed a fairly steady progression from one side of the region to the other. The sites and their coordinates are given in table I. Some of the more fruitful sources of data are given in the references. Their data are plotted in fig. 1, with the sites in order of increasing east longitude, but arbitrarily separated to avoid overlapping of plots. Also shown in fig. 1, for illustrative pur- 
poses only, are quadratic functions of time fitted, using least squares, to these data.

\section{Estimates of drift rates}

The actual time of minimum at a site is poorly defined, partly because of the flatness of the curve and partly because of the scatter in the observations. Also, in some cases, it depends only on the data observed near the time of minimum and ignores the remoter observations. To avoid these shortcomings, we choose to consider the whole curve, displacing it in time and adjusting the baseline and amplitude to obtain the best match with the London curve. London is chosen as the reference site because of the length and completeness of its data. The optimum lag (or lead), $T$, is that which maximises the coefficient of correlation, $k$, between the two sets of data. Since the data are observed at irregular intervals, it is necessary to interpolate before $k$ can be calculated. For the London curve we use the 5-yearly values obtained by Malin and Bullard (1981) from fitting least-squares spline functions to their data and used by them in their fig. 4. The curves for the other sites are each defined by a cubic spline fitted either to the observed values or, where sufficient data are available, to approximately 5-year unweighted means of the data. The actual spacing of the means is dictated by the data distribution, but is chosen to be about 5 years to match the resolution of the London data. Because the latest time of minimum occurs at about 1880 only pre1900 data are included. It should be noted that the cubic splines used here are merely employed to interpolate between observed values, or means of observed values, and do not involve any further smoothing. The (unshifted) cubic splines are plotted in fig. 2, in the same order as in fig. 1. For each time-displacement (they are in steps of $0.1 \mathrm{yr}$ ) the cubic spline is used to interpolate values of $D$ at times corresponding to the London data and these are used to compute $k$. The values of $T$ and $k$ for each site are given in

Table I. Site positions and values of the optimum lag or lead time $T$ and the associated correlation coefficient $k$ between the declination data from the site and those from London.

\begin{tabular}{lcccc}
\hline \hline \multicolumn{1}{c}{ Site } & $\begin{array}{c}\text { Latitude } \\
\left({ }^{\circ}\right)\end{array}$ & $\begin{array}{c}\text { Longitude } \\
\left({ }^{\circ}\right)\end{array}$ & $\begin{array}{c}T \\
(\mathrm{yr})\end{array}$ & $k$ \\
\hline Azores & 38.0 & -27.0 & -50.1 & 0.979 \\
Berlin & 52.5 & 13.4 & 12.7 & 0.963 \\
Cadiz & 36.5 & -6.3 & -7.9 & 0.987 \\
Copenhagen & 55.7 & 12.6 & 5.6 & 0.995 \\
Dublin & 53.3 & -6.2 & -3.6 & 0.997 \\
Istanbul & 41.0 & 29.0 & 63.0 & 0.986 \\
Lisbon & 38.7 & -9.1 & -9.5 & 0.997 \\
London & 51.5 & 0.0 & 0.0 & $(1.000)$ \\
Oslo & 59.9 & 10.7 & 2.6 & 0.997 \\
Paris & 48.8 & 2.5 & -5.1 & 0.998 \\
Rome & 41.9 & 12.5 & 20.6 & 0.995 \\
St. Petersburg & 59.9 & 30.4 & 13.7 & 0.903 \\
\hline Agincourt & 43.8 & -79.3 & - & - \\
Cape Town & -33.9 & 18.5 & -24.5 & 0.994 \\
Cheltenham & 38.7 & -76.8 & - & - \\
St. Helena & -16.0 & -5.7 & -29.2 & 0.996 \\
\hline
\end{tabular}




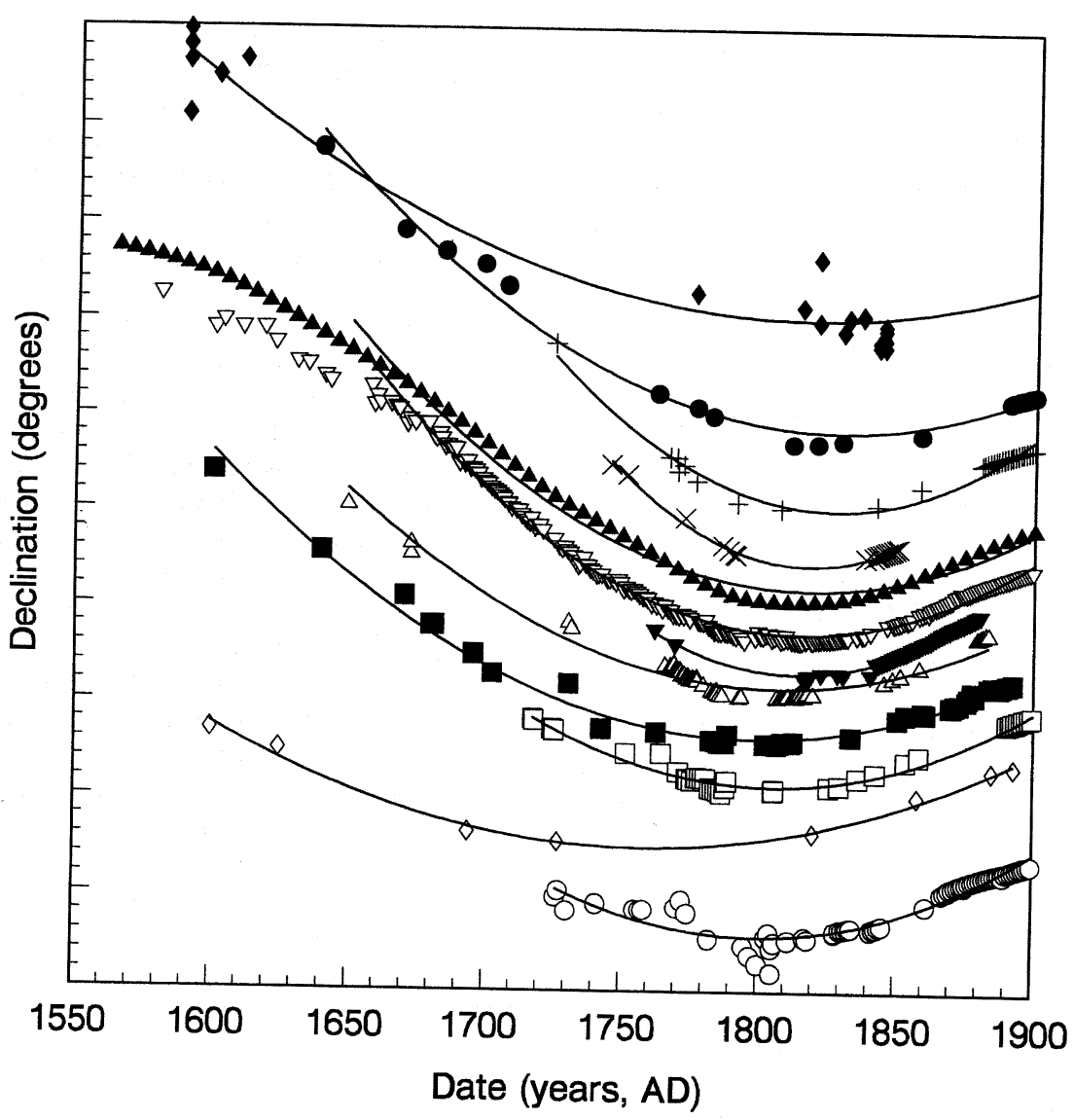

Fig. 1. Declination values plotted as a function of date of observation. The data for the 12 sites are plotted in order of increasing east longitude with the most westerly site, the Azores, at the top. The values have been separated by arbitrary amounts to prevent overlapping; hence no declination values are given on the vertical axis. The distance between the larger tick marks on this axis corresponds to $10^{\circ}$. The key to sites is as follows: - Azores; • Lisbon; + Cadiz; $\times$ Dublin; $\wedge$ London; $\nabla$ Paris; $\nabla$ Oslo; $\Delta$ Copenhagen; $\square$ Rome; $\square$ Berlin; $\diamond$ Istanbul; $\circ$ St. Petersburg. The lines (included for illustrative purposes) are least-squares quadratic fits to the plotted data.

table I. A positive sign for $T$ indicates that the curve for that site is ahead of that for London. An examination of the curves shows that no value of $T$ is inconsistent with the (subjective and much less well determined) differences between times of minima.

It is not easy to estimate the errors of isolated early $D$ measurements since they include both errors of measurement (which depend on the skill and equipment of the observer) and site differences. For London, where the early curve is well defined by many observations, 23 site differences from Greenwich, at distances of up to $40 \mathrm{~km}$, varied from $-22^{\prime}$ to $34^{\prime}$ (Malin and Bullard, 1981, table 2), with a root mean square (r.m.s.) of $16^{\prime}$. After correction for site differences, 24 isolated 18th century observations departed from the best estimate (Malin and Bullard's smoothed cubic spline) by from $1^{\prime}$ to $46^{\prime}$, with r.m.s. $20^{\prime}$. Thus, we might expect the error of an individual observation made between 1700 and 1800 to be about $0.5^{\circ}$. From 1800 , 


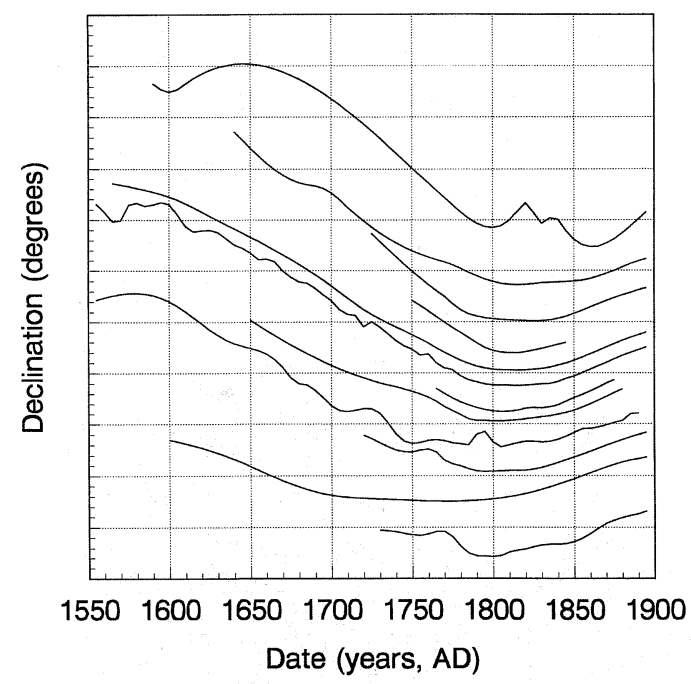

Fig. 2. The cubic splines used to compute the optimum lag or lead times and the correlation coefficients. The order of the curves and the vertical axis scale are the same as in fig. 1.

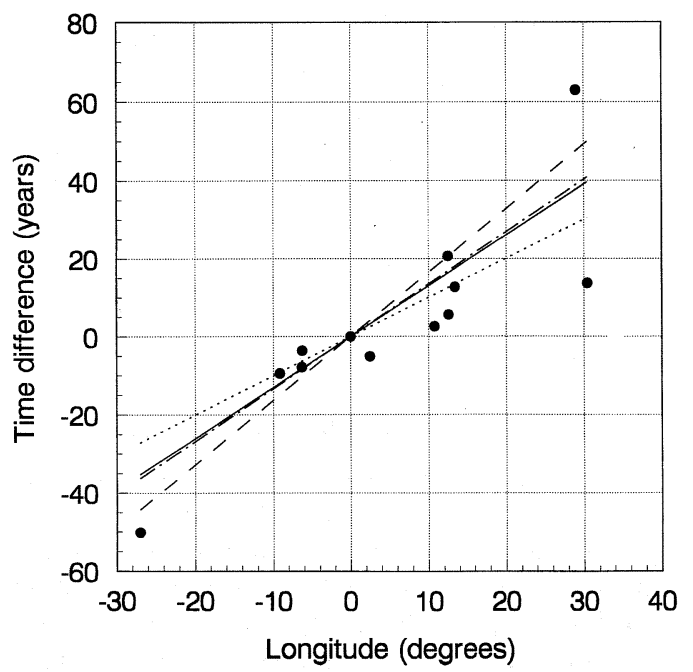

Fig. 3. Optimum lag or lead time $(T)$ for the 12 sites plotted against longitude $(\bullet)$. The 4 lines are leastsquares linear regression lines using all 12 points (solid line); omitting the value for St. Petersburg (dashed line); omitting that for Istanbul (dotted line); and omitting those for St. Petersburg and Istanbul (dot/ dash line). most of the data are means of series of observations or (after about 1850) observatory annual means. This does not affect site differences, but should greatly reduce observational errors.

It is expected that the errors would be randomly distributed, but it is interesting to see what would happen in the worst possible case when all the observations before the minimum are too far east by $0.5^{\circ}$ and all those after the minimum too far west by $0.5^{\circ}$. When the data are re-analysed after «correction» for such errors (leaving London unchanged) the only lags to change by more than 5 years are those for Berlin (5.1 yr), St. Petersburg (5.7 yr) and Istanbul (6.1 yr). All changes are in the same sense. This shows the robustness of the method and its relative insensitivity to errors even as large and systematic as those postulated above.

A plot of $T$ against longitude (fig. 3 ) shows a reasonably linear relation with a westward drift rate of $0.77 \pm 0.15^{\circ} \mathrm{yr}^{-1}$, determined by least squares. The two most disparate sites are Istanbul and St. Petersburg. While the latter has a lower value for $k$ (indeed, the lowest $k$ for any of the sites), it is based on more data than for Istanbul. Omission of Istanbul gives a westward drift of $1.00 \pm 0.23^{\circ} \mathrm{yr}^{-1}$; omission of St. Petersburg gives $0.61 \pm 0.08^{\circ} \mathrm{yr}^{-1}$; omission of both gives $0.74 \pm 0.13^{\circ} \mathrm{yr}^{-1}$, which is close to the value obtained when both are included. In each of these four fits the straight line was constrained to pass through the origin (representing London) since London has been taken as the reference site throughout.

There is no obvious dependence on latitude, as can be seen from fig. 4 , in which $T$ is indicated by the length of the arrow originating from each site, positive to the east and negative to the west.

It is interesting to note that the $D$ data for Cape Town and St. Helena also show a similar pattern to the European sites, but because of their remoteness and the lack of any intervening sites to give confirmation of continuity we have omitted them from this study. We have found no suitable sites to the east of Europe, where the feature might be expected to occur earlier and hence require even older data for its elucidation. Data are available (at Agincourt and Cheltenham) for its predicted time of arrival in Ameri$\mathrm{ca}$, but they do not show the feature. 


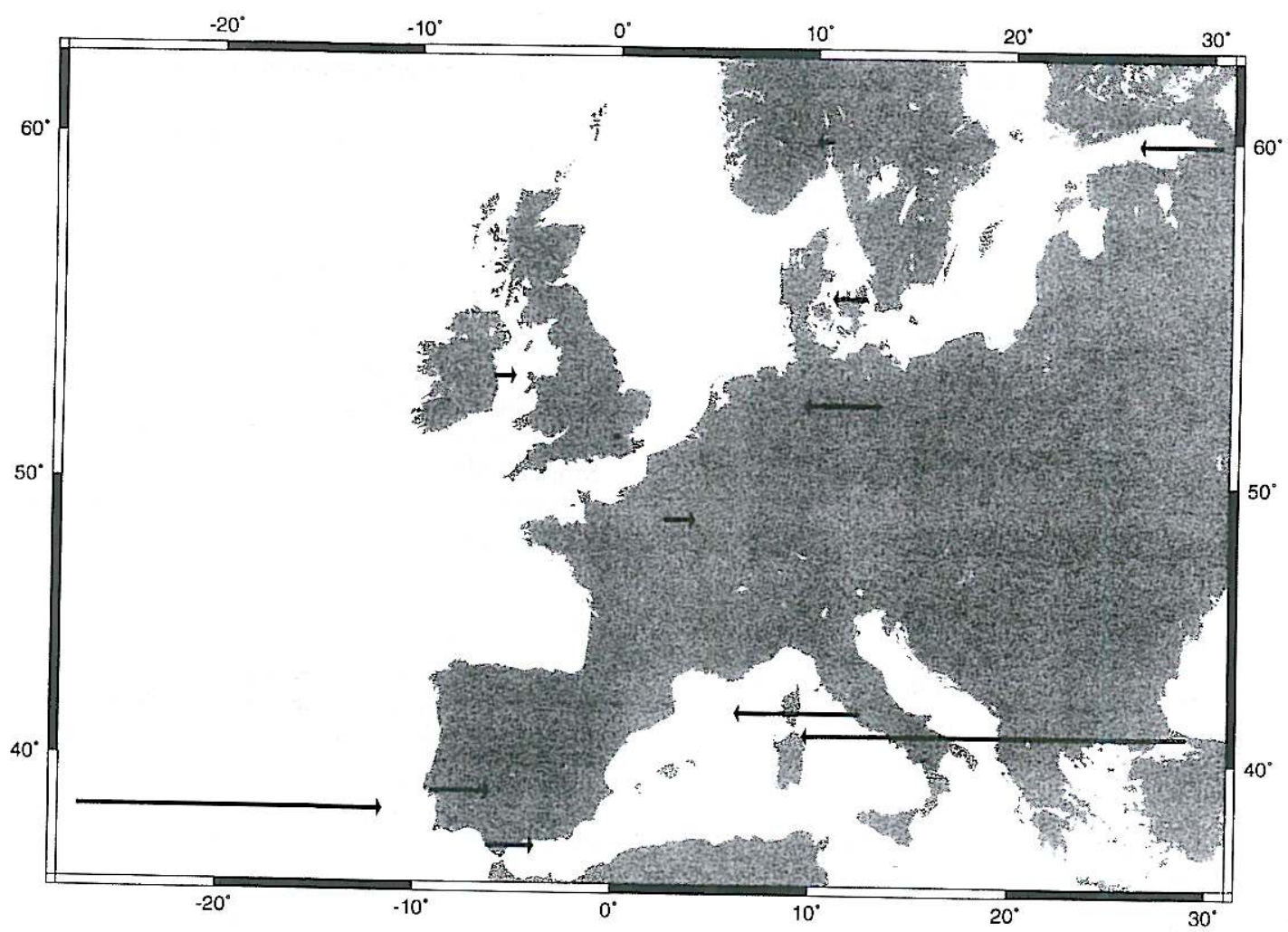

Fig. 4. Pictorial representation of $T$. Its value is represented by an arrow whose base is at the site concerned, whose length is proportional to $T$, and whose direction gives the sign of $T$-to the east for negative and to the west
for positive values.

\section{A comparison with modelled secular variation}

In an attempt to compare the observed values of $D$ and the times of minima with those given by global models of the secular variation we synthesised values of $D$ at the 12 sites in the first part of table I and at 5-yearly intervals from the models of Bloxham and Jackson (1992). These models represent the main geomagnetic field and its secular variation over the non-overlapping intervals 1690 to 1840 and 1840 to 1990 using cubic B-splines to describe the temporal variation of the field.
Using the method described in Section 3, these computed values were used to estimate times of minimum $D$ by finding the optimum lag (or lead) $(T)$ between the computed values at the other sites and (1) the observed values at London, and (2) the computed values at London. Table II gives the results of these comparisons. Comparison with the «observed» values in table I indicates that the observed value of $T$ for St. Petersburg is anomalous for some reason. On the basis of r.m.s. differences between the two sets of values of $T$ in table II and those in table I, a reasonable estimate of the uncertainty in the latter values is about \pm 5 years. 
Table II. Values of the optimum lag or lead time $T$ between declination values computed at the site from the models of Bloxham and Jackson (1992) and (1) values observed at London, and (2) values computed from the models at London.

\begin{tabular}{lrr}
\hline \hline \multirow{2}{*}{ Site } & \multicolumn{2}{c}{$T(\mathrm{yr})$} \\
\cline { 2 - 3 } & \multicolumn{1}{c}{$(1)$} & \multicolumn{1}{c}{$(2)$} \\
\hline Azores & -43.3 & -35.9 \\
Berlin & 13.0 & 14.5 \\
Cadiz & -5.6 & -0.9 \\
Copenhagen & 8.7 & 10.1 \\
Dublin & -9.7 & -5.9 \\
Istanbul & 63.5 & 66.4 \\
Lisbon & -9.9 & -4.6 \\
London & -2.9 & 0.0 \\
Oslo & 2.6 & 3.5 \\
Paris & 1.6 & 4.0 \\
Rome & 20.8 & 23.2 \\
St. Petersburg & 63.2 & 65.7 \\
\hline
\end{tabular}

\section{Conclusions}

The comparisons described in Section 4 indicate that the «observed» value of $T$ for St. Petersburg should be regarded as anomalous. Our preferred estimate for the westward drift rate is therefore that which does not include this St. Petersburg value: $0.61 \pm 0.08^{\circ} \mathrm{yr}^{-1}$.

It is not our intention in this short note to discuss possible mechanisms for the westward drift. Suffice it to say that attempts to model the feature discussed here in terms of dipoles, following Malin and Bullard (1981), was not successful.

It is interesting to recall that Halley (1692) estimated 700 years for a complete rotation of the magnetic field, implying a westward drift of $0.51 \mathrm{yr}^{-1}$. Since his data were nearly all $D$ values from Europe, his estimate may be much better than has hitherto been assumed. It is appropriate to acknowledge that Bauer (1895) also noted the widespread minimum in $D$ and tabulated its date of occurrence at a number of sites.

\section{Acknowledgements}

We thank Mioara Alexandrescu for supplying a computer file containing the Paris data. We also thank Susan Macmillan for producing fig. 4, using the GMT software (Wessel and Smith, 1991). This paper is published with the approval of the Director, British Geological Survey (NERC).

\section{REFERENCES}

AleXANDRESCU, M., V. COURTILlot and J.-L. LE MouËL (1996): Geomagnetic field direction in Paris since the mid-sixteenth century, Phys. Earth Planet. Inter., 98, 321-360.

BAUER, L.A. (1895): On the secular motion of a free magnetic needle. II, Phys. Rev., 3, 34-48.

BLOXHAM, J. and A. JACKSON (1992): Time-dependent mapping of the magnetic field at the core-mantle boundary, J. Geophys. Res., 97, 19537-19563.

Cafarella, L., A. De Santis and A. Meloni (1993): Il Catologo Geomagnetico Storico Italiano, Istituto Nazionale di Geofisica, Roma.

HALLEY, E. (1692): An account of the cause of the change of the variation of the magnetical needle; with an hypothesis of the structure of the internal parts of the Earth, Philos. Trans. R. Soc. London, 17, 563-578.

LANGEL, R.A. (1987): The main field, in Geomagnetism, edited by J.A. JACOBS (Academic Press, London), vol. 1, 249-512.

MALIN, S.R.C. (1969): Geomagnetic secular variation and its changes, 1942.5-1962.5, Geophys. J. R. Astron. Soc., 17, 415-441.

MALin, S.R.C. and Sir EdWARD Bullard (1981): The direction of the Earth's magnetic field at London, 15701975, Philos. Trans. R. Soc. London, Ser. A, 299, 357-423.

WESSEL, P. and W.H.F. SMITH (1991): Free software helps map and display data, Eos Trans. Amer. Geophys. Un., 72, 441-448.

(received June 18, 1998; accepted January 13, 1999) 